\title{
A Rodada Doha, as mudanças no regime do comércio internacional e a política comercial brasileira
}

Doha Round, changes in the international trade regime, and the Brazilian commercial policy

Rev. Bras. Polít. Int. 55 (1): 174-193 [2012]

\section{Introdução}

O comércio internacional vem passando por profundas transformações nos últimos anos. Em 1947, ano em que o Acordo Geral sobre Tarifas e Comércio (Gatt) foi assinado, a fração de mercadorias exportada representava apenas 7\% do total da produção mundial. Em 2001, quando a Rodada Doha da Organização Mundial de Comércio (OMC) foi lançada ${ }^{1}$, mais de um quarto da produção mundial era transacionada internacionalmente. Entre 1947 e 2001, o volume de comércio tornou-se aproximadamente 22 vezes maior, englobando serviços além de commodities e produtos manufaturados ${ }^{2}$. Paralelamente ao grande aumento nos fluxos comerciais nas últimas décadas, observou-se a gradual fragmentação e dispersão da produção industrial, gerando novas dinâmicas de trocas internacionais intra e entre empresas. Durante os dez anos de negociação da Rodada Doha (2001-2011), essas mudanças na estrutura do comércio internacional tornaram-se ainda mais evidentes, impulsionadas pela consolidação de países emergentes como proeminentes atores no cenário de comércio global, com destaque para a China.

Em estudo publicado pela Organização para a Cooperação e Desenvolvimento Econômico (OCDE), Bonaglia e Goldstein (2007) fazem referência à existência de "uma nova geografia do comércio internacional" ligada ao rápido avanço da globalização dos processos produtivos por meio das "cadeias de valor globais (CVG)”. A emergência das CVGs tornou-se viável principalmente pelos avanços

\footnotetext{
* Doutoranda em Relações Internacionais pela Universidade de Brasília (UnB) (susan@unb.br).

** Professor do Instituto de Relaçōes Internacionais da Universidade de Brasília (IREL/UnB) (rel.sato@gmail.com). 1 A Rodada de Doha foi oficialmente lançada pela IV Reunião Ministerial da Organização Mundial do Comércio, em Doha, no Catar, em novembro de 2001.
}

2 OMC, World Trade Reports, 2002, 2005. 
nas tecnologias da informação, pelo declínio nos custos de transporte e pelo surgimento de novas formas de organizar a produção, fazendo surgir conceitos como "produção modular" e "manufatura flexível". Para Dicken (2003), a economia global se transformou em uma "estrutura caleidoscópica e altamente complexa", envolvendo a fragmentação de processos produtivos e sua realocação geográfica em escala global.

A desagregação e dispersão geográfica da produção gerou profundos impactos no comércio internacional. A gama de produtos e serviços que são comercializados internacionalmente se expandiu de forma considerável acompanhando o movimento de capitais e os investimentos em tecnologias que se tornaram muito mais fluidos e dispersos do que eram anteriormente (Dymond e Hart 2008). Essa dimensão do processo de globalização virtualmente eliminou a tradicional noção de que, no comércio internacional, são transacionados primordialmente commodities e produtos acabados. ${ }^{3}$

Como observamos, em 2001, quando os países-membros da Organização Mundial de Comércio lançaram a Rodada Doha, esse novo cenário do comércio internacional marcado pela globalização econômica já estava em pleno vigor. No entanto, negociadores acordaram um mandato negociador ${ }^{4}$ nos moldes das rodadas anteriores ${ }^{5}$ à criação da $\mathrm{OMC}$, não levando em conta os desafios impostos pelas novas dinâmicas do comércio internacional. Dessa forma, a agenda de Doha e seu mandato revelaram-se alheios a essas mudanças e ajudam a explicar por que Doha já nasceu obsoleta.

Ao longo dos dez anos de negociação da Rodada, os impactos da globalização da produção tornaram-se ainda mais evidentes, mas não foram efetivamente incorporados em sua agenda. Essa desconexão entre as novas realidades da economia internacional e o espírito negociador da Rodada seria uma das grandes causas de seu insucesso. Dessa forma, buscamos analisar neste trabalho a hipótese de que as razões pelas quais a Rodada não produziu um desfecho até o momento são de ordem estrutural, embora as explicações mais corriqueiras enfatizem os impasses como resultantes da falta de capacidade dos negociadores em acordarem concessões satisfatórias que pudessem levar os países-chaves a aceitar o pacote de Doha.

$\mathrm{O}$ presente artigo argumenta, ademais, que tal descompasso reside, na realidade, nos próprios países-membros da OMC que, em sua maioria, ainda não pautam suas políticas comerciais e suas estratégias de inserção internacional por essas novas dinâmicas do comércio internacional, o que se reflete em suas posições

3 Segundo dados da OMC, em 2009, o comércio de bens intermediários foi o setor mais dinâmico do comércio internacional, representando mais de $50 \%$ do comércio global (excluindo o comércio de petróleo e derivados).

4 Vide "Declaração Ministerial de Doha", disponível em <http://www.wto.org/english/thewto_e/minist_e/ min01_e/mindecl_e.htm>. Acesso em 27 de outubro de 2011.

5 Durante a vigência do Gatt, oito rodadas de negociações tarifárias foram realizadas: Genebra (1947); Annecy (1949); Torquay (1950-1951); Genebra (1956); Dillon (1960-1962); Kennedy (1964-1967); Tóquio (1974-1979), e, finalmente, a Rodada Uruguai (1986-1993). 
nas negociações multilaterais. O Brasil seria um exemplo típico desse numeroso grupo de países cujas agências e mecanismos de promoção comercial baseiam-se essencialmente em concepções tradicionais de fomento à exportação de produtos acabados. Haveria ainda no Brasil um agravante dessa prática anacrônica, que seria a tendência à proteção do mercado nacional contra a importação de partes e componentes.

Uma primeira tarefa deste trabalho foi identificar as novas realidades do comércio internacional, destacando o processo pelo qual as dinâmicas das CVGs passaram a orientar grande parte do comércio. Assim, inicialmente, será analisada a evolução teórica do modelo de CVGs. Em seguida, serão discutidos os impactos dessa nova forma de estruturação do comércio internacional sobre o sistema multilateral de comércio, em particular os desafios colocados às negociações da Rodada Doha da OMC. Na terceira parte, usando como referência o caso do Brasil, serão apresentadas e, na medida do possível, avaliadas as formas pelas quais as políticas comerciais tradicionais baseadas essencialmente em negociações de acordos de liberalização comercial para produtos nacionais acabados tornaramse inadequadas às novas estruturas de produção e aos novos canais pelos quais transitam a maior parte do comércio internacional, refletindo negativamente nas negociações da OMC. Como conclusão geral, a expectativa é que, em países como o Brasil, o debate sobre o comércio internacional seja colocado em outras bases, levando em conta essas questões que, ao longo das últimas décadas, remodelaram amplamente a forma como as trocas comerciais são conduzidas neste mundo de relaçōes globalizadas.

\section{A evolução do modelo de CVGs}

A crescente fragmentação e dispersão geográfica da atividade econômica é uma das principais características desse novo modelo de comércio integrado, onde as empresas dispõem de várias formas de engajamento na economia global, quer seja como compradores, ou provedores, ou vendedores, ou distribuidores, ou consultores ou prestadores de serviços (Sturgeon 2008). O conceito de CVG surge para descrever esse novo arranjo produtivo, que inclui o conjunto de atividades realizadas por agentes localizados em diferentes países desde a concepção de um produto até o seu "pós-consumo", isto é, design, produção, marketing, distribuição e apoio ao consumidor final. Em recente estudo concluído pela OMC e pelo Institute of Developing Economies (IDE-JETRO), o comércio de produtos intermediários resultante dessa fragmentação de atividades ao longo da cadeia de produção é chamado de "trade in tasks", ou seja, "comércio de tarefas". ${ }^{6}$

6 World Trade Organization - IDE-JETRO. "Trade Patterns and global value chains in East Asia: from trade in goods to trade in tasks". IDE-JETRO and World Trade Organization, 2011. Disponível em <http://www.wto. org/english/res_e/booksp_e/stat_tradepat_globvalchains_e.pdf>. 
O conceito de CVG deriva dos trabalhos de Hopkins e Wallerstein (1977; 1986) sobre cadeias de commodities globais (CCG), que destacam o poder do Estado em moldar os sistemas globais de produção, por meio de tarifas e regras de conteúdo local aplicadas sobre o comércio de produtos. Gereffi e Korzeniewicz (1994) retomam esse conceito de CCG, mas tendo como principal ator a firma em vez do Estado, argumentando que em contextos de liberalização comercial, a capacidade do Estado em aplicar tarifas e regras de conteúdo local ficam limitadas. Nessa obra, Gereffi e Korzeniewicz desenvolvem a premissa de que um novo sistema produtivo global estaria emergindo, onde a integração econômica iria além do comércio internacional.

Essa corrente de pensamento de economia internacional desafia ferramentas clássicas da economia comumente usadas para explicar o comércio, especialmente teorias de oferta e demanda e vantagens comparativas dos países (Flexor 2009). Ou seja, a abordagem de cadeias globais tem como nível de análise as empresas (agentes e elos de cadeias produtivas), em vez dos países ou, mais exatamente, dos Estados como agentes que determinam parcerias comerciais. Nesse modelo, o comércio reflete os interesses das empresas transnacionais e a forma como elas exercem controle sobre fluxos de produtos e serviços globais, em um ambiente de extrema fragmentação dos processos produtivos e dispersão geográfica.

Como apontado por Dicken (2003), os aspectos mais importantes na análise de cadeias de produção são (i) a forma como a cadeia é coordenada e regulamentada e (ii) sua configuração geográfica. Dicken argumenta que existem dois níveis de coordenação das cadeias de produção. $\mathrm{O}$ primeiro nível seria aquele exercido pelas firmas (particularmente as transnacionais), por meio das várias formas de relacionamentos enquadradas em um sistema econômico. Dicken faz uso dos dois modelos de coordenação de cadeia desenvolvidos por Gereffi e Korzeniewicz (1994):

a) Producer-driven: referem-se às cadeias onde corporações transnacionais controlam o conjunto de fornecedores e distribuidores que compõem o sistema de produção. Alguns exemplos desse tipo de cadeia são as indústrias automotivas, de avióes, computadores, máquinas elétricas etc.

b) Buyer-driven: referem-se às cadeias coordenadas por grandes compradores internacionais, tais como varejistas (Walmart, Carrefour etc.), proprietários de marcas reconhecidas internacionalmente (Nike, GM, Honda, Fisher Price etc.) e tradings.

Dicken considera que o Estado é quem exerce o segundo nível de coordenação sobre as cadeias de produção, em contraposição a outros autores que defendem que o Estado está, na realidade, desaparecendo em função da globalização (Reich 1991; Ohmae 1995). Para Dicken, todos os elementos na cadeia de produção são regulados por uma estrutura política cuja unidade básica é o Estado-nação. Assim como nas firmas transnacionais, o comportamento dos Estados varia conforme 
sua composição cultural, política e social, e sua posição no espectro ideológico, enquanto as firmas, por sua vez, têm necessariamente que operar segundo os sistemas regulatórios nacionais e internacionais. Stopford e Strange (1991) chamam de "nexo triangular" as interaçōes entre firmas-firmas, Estado-Estado e Estado-firma. Ainda segundo Dicken, a nova economia internacional estaria sendo moldada e reestruturada pelas interaçôes complexas e dinâmicas desse nexo triangular entre firma e Estado.

Sturgeon (2008) chama atenção para o fato de que a tipologia buyer-driven/ producer-driven está baseada em uma visão estática e empírica da tecnologia e das barreiras de entrada, mas que na realidade ambas são dinâmicas devido às mudanças tecnológicas e ao aprendizado das empresas e dos setores (Henderson et al. 2002). Para Sturgeon, uma abordagem mais dinâmica acerca da governança das cadeias leva a duas constataçôes. A primeira delas diz respeito ao fato de muitas indústrias estarem deixando de seguir o modelo de integração vertical do tipo producer-driven; a segunda constatação aponta para o fato de que o modelo buyer-driven não é capaz de capturar todos os arranjos de governança em rede atualmente observados.

É nesse contexto que surgiu na última década a discussão sobre a necessidade de aperfeiçoar e fazer avançar esse modelo estático das CCGs. Desenvolve-se, dessa forma, o modelo de CVG, que busca dar conta das mudanças observadas nas cadeias de produção e prever possíveis desenvolvimentos futuros. As tipologias de governança internacional das cadeias de produção teriam evoluído dos modelos producer-driven/buyer-driven para um modelo muito mais complexo e dinâmico.

Segundo o modelo de governança de CVGs desenvolvido em Gereffi et al. (2005), existem cinco formas genéricas em que as firmas podem coordenar ou "governar" as conexões entre as atividades da cadeia de valor global: 1) conexões simples de mercado, governadas por relações de preço e pela facilidade de encontrar e trocar fornecedores e compradores; 2) conexōes modulares, onde as informações complexas sobre as transaçôes são codificadas e na maioria das vezes digitalizadas antes de serem enviadas a fornecedores altamente competentes; 3) conexóes relacionais, onde informação tácita é trocada entre compradores e fornecedores altamente competentes; 4) conexões cativas, onde fornecedores menos competentes recebem instruções detalhadas; e 5) conexōes dentro da mesma empresa, governadas por relações de hierarquia. Os autores apontam três variáveis-chaves que atuam sobre as cinco formas de governança das CVGs, combinando-se em grau e intensidade variados e imprimindo padróes distintos no relacionamento: (i) a complexidade de informaçōes trocadas entre as diferentes tarefas da cadeia de valor; (ii) as possibilidades de se codificar essas informaçôes; e (iii) as capacidades e habilidades dos fornecedores.

Esse modelo de governança das CVGs tem sido usado para compreender por que algumas atividades da cadeia são fáceis de serem realocadas geograficamente, enquanto outras permanecem enraizadas em determinado local (Sturgeon 2008). O modelo de governança modular tem sido reconhecido como o mais moderno, 
visto que ele permite uma forte coordenação de atividades à distância, mesmo em setores de alta complexidade, como em indústrias de tecnologia intensiva. Por outro lado, o modelo de conexões relacionais requer que as firmas estejam localizadas proximamente, para a troca de informação tácita, o que incentiva a formação de clusters industriais (Gluckler 2007).

É importante ressaltar, entretanto, que esses cinco padrões de governança expostos acima são tipos ideais (Sturgeon, 2008). O que se observa no mundo real é uma mistura das várias formas de governança dentro de determinado setor produtivo, cadeias de valor, firmas e mesmo em um único estabelecimento. Esses padrões de governança servem como base para pesquisadores e tomadores de decisão entenderem as múltiplas formas de conexão nas cadeias de valor. Com base nesse instrumental, policy makers podem formular políticas comerciais que propiciem a entrada de empresas nessas cadeias de produção, gerando aumento de comércio e adensamento da atividade industrial no país.

A análise da dinâmica de governança das CVGs oferece uma contribuição substancial para a compreensão do comércio internacional. Sob a ótica das CVGs, os tomadores de decisões, tanto em países desenvolvidos como em países em desenvolvimento, têm condiçóes de avaliar mais adequadamente as formas de acesso aos mercados internacionais, as barreiras de entrada enfrentadas por pequenas e médias empresas, e o posicionamento nas CVGs mesmo nos casos de atividades que exigem mão de obra intensiva. Como observado por Flexor (2009), é interessante notar que tanto nas negociações comerciais quanto na formulação de políticas comerciais, o foco tem sido nas discussões de tarifas, subsídios e outros instrumentos tradicionais de política comercial - a discussão sobre a organização das cadeias globais tem sido um aspecto virtualmente ausente nas mesas de negociação comercial. Nas negociações de Doha não tem sido diferente. A visão de que um conjunto expressivo de restrições e oportunidades comerciais reside na própria forma como as CVGs estão organizadas e são coordenadas ainda é marginal em muitos países, particularmente no Brasil, o que se reflete nas negociações da OMC.

\section{O sistema multilateral de comércio, a Rodada Doha e as CVGs}

A análise do sistema internacional de comércio, sob o enfoque tradicional, costuma levar em consideração três aspectos centrais: i) o conjunto de regras e compromissos estabelecidos pelo Gatt e OMC; ii) as negociações multilaterais de liberalização comercial; e iii) os acordos regionais de preferências tarifárias. Em todos esses aspectos, o Estado é visto como o principal agente do comércio, capaz de negociar preferências tarifárias, comprometer-se com regras e gerenciar aduanas e, com isso, orientar a adoção de padrões de comércio que, presumivelmente, convém aos interesses identificados como "nacionais". 
No entanto, a emergência das CVGs como forma de organização do comércio internacional traz um importante componente à análise, ainda comumente negligenciado: o papel das empresas e suas relaçōes de interdependência nas CVGs. Nesse ponto, destaca-se não somente a atuação das grandes empresas multinacionais principais coordenadoras das cadeias, mas também das pequenas empresas participantes nas redes globais de trocas. $\mathrm{Na}$ última década, os instrumentos tradicionais de política comercial e as formas de se mensurar o comércio, assim como o modelo de comércio estabelecido pela OMC e os acordos tarifários, passaram a ser questionados em face das profundas transformações geradas pela desagregação e dispersão da produção na lógica das CVGs.

Dymond e Hart (2008), por exemplo, argumentam que a emergência de uma economia global tem minado a premissa central de sustentação do sistema multilateral de comércio - a de que governos são os atores principais na determinação dos fluxos internacionais de comércio. Segundo os autores, diante da nova economia internacional, o modelo de comércio estabelecido com o Gatt e a OMC e os acordos preferenciais estariam se tornando irrelevantes. Além disso, argumentam que algumas das premissas centrais desse modelo de governança global por meio do Gatt e atualmente da OMC teriam alto potencial de gerar resultados econômicos perversos sob a lógica das CVGs: (i) a troca de obrigaçôes e direitos entre "pares" ou pequenos grupos de países; (ii) o princípio-chave da OMC de "reciprocidade", que seria destrutivo para empresas que são partes de CVGs; (iii) o caráter relativo do princípio de tratamento nacional; e (iv) a aplicação de medidas de defesa comercial, que seria contrária à eficiente operação das cadeias globais.

Outros autores, como Pierre Sauvé (2001), chamam a atenção para o crescente descompasso entre o acelerado ciclo de produção e inovação que as empresas enfrentam nos mercados globais e o lento ciclo negociador capitaneado pelos governos nas negociaçôes multilaterais de comércio. Tal descompasso estaria minguando o entusiasmo do setor privado na busca pelo multilateralismo e estimulando iniciativas que possam ser conduzidas sem a participação dos agentes governamentais. É notório que, desde o início da Rodada Doha, o engajamento do setor privado nas negociações tenha sido sempre marginal. Ao longo dos dez anos da Rodada, esse interesse foi diminuindo ainda mais em face da crescente desconexão dos temas tratados com a realidade da economia global. Para muitas empresas, barreiras tarifárias passaram a ser somente mais um custo transacional, ao lado de custos logísticos ou de infraestrutura. Ademais, em vista da proliferação de acordos de preferência tarifária no sistema internacional, a promessa de maior acesso a mercados por meio de redução tarifárias oferecida pela Rodada Doha não foi suficiente para entusiasmar grande parcela do setor privado.

É crescente o entendimento de que o setor privado estaria sendo atraído por caminhos não governamentais para assegurar acesso a mercados e o estabelecimento de padrões e normas para seus produtos. Kaisa Sorsa (2010) destaca o significativo aumento da "autorregulação" colocado em prática por crescente número de 
empresas nas CVGs, argumentando que a evolução das estruturas globais de produção tem desafiado de muitas formas a regulação convencional realizada usualmente pela OMC. Para a autora, o estabelecimento de normas técnicas e padrões pelo setor privado não deveria ser visto como mais uma barreira ao comércio, mas uma tentativa de suprir lacunas de regulamentação em um ambiente de rápida evolução de processos e produtos.

É importante notar que, nos principais documentos referentes às negociações da Rodada Doha da OMC, pouca ou nenhuma referência foi encontrada sobre as novas dinâmicas do comércio internacional e a necessidade de adaptação ou evolução das regras do sistema multilateral de comércio em resposta à nova realidade. Não estão incluídos na agenda negociadora temas menos convencionais como novas regras de origem para bens produzidos em cadeias globais; ou modernização da legislação antidumping para incluir maneiras de se taxar toda uma cadeia de valor de um produto. Em uma agenda que se declara ser "para o desenvolvimento", não é foco das discussões incentivos para que países pobres fomentem a inserção de pequenas e médias indústrias em cadeias globais, ou até mesmo subsídios que pudessem ser permitidos para que empresas de determinado país possam assumir uma posição mais alta na cadeia de valor por meio do desenvolvimento tecnológico.

Nos últimos dois anos, em vista do impasse da Rodada Doha, é perceptível um movimento por parte do próprio secretariado da OMC com vistas a fomentar a discussão sobre possíveis respostas para os novos desafios do comércio internacional, como válvula de escape para uma possível derrocada nas negociações da Rodada. A OMC vem promovendo estudos acerca das implicações da lógica das CVGs na maneira como se fazem as estatísticas do comércio internacional e como se mensura a agregação de valor nas diferentes etapas produtivas executadas em países diversos.

Ademais, a OMC lançou recentemente a iniciativa Made in the World ${ }^{7}$, que reconhece a dispersão internacional da produção e busca novas formas de posicionamento frente a regras de origem em um mundo onde a natureza das relações comerciais vem se tornando uma relação de maior integração e interdependência entre os agentes econômicos situados em diferentes países. Por meio dessa iniciativa, a Organização abre também espaço para discussão de novas metodologias para a elaboração de estatísticas comerciais, com base no valor agregado em cada etapa da produção. Com isso, a OMC busca destacar que o uso de estatísticas tradicionais em um cenário de produção globalizada estaria levando a interpretações errôneas de possíveis desequilíbrios comerciais entre os países.

Em paralelo, o secretariado da OMC publicou recentemente um estudo em conjunto com o IDE-JETRO ${ }^{8}$, analisando os impactos das CVGs nos padróes

7 Disponível em <http://www.wto.org/english/res_e/statis_e/miwi_e/miwi_e.htm>. Acesso em 30 de outubro de 2011.

8 "Trade Patterns and Global Value Chains in East Asia: from trade in goods to trade in tasks". Disponível em $<$ http://www.wto.org/english/res_e/booksp_e/stat_tradepat_globvalchains_e.pdf>. Acesso em 25 de outubro de 2011. 
comerciais no leste asiático. Tal trabalho destaca as novas dinâmicas comerciais na região, enfatizando a evolução do modelo comercial tradicional de trocas de produtos acabados entre os países para uma nova tendência onde predomina o comércio de "tarefas" em um ambiente produtivo interconectado e interdependente.

É importante notar, no entanto, que essas iniciativas de modernização das discussóes sobre o comércio internacional têm partido da OMC (atualmente sob a chefia de Pascal Lamy) como instituição, e não dos países-membros da Organização. Como destacamos anteriormente, a grande maioria dos governos ainda não processou as novas realidades do comércio globalizado de forma que pudesse refletir em novos posicionamentos no âmbito da OMC.

Consideramos que o Brasil esteja no meio desse vasto número de países que continua pautando sua política comercial em conceitos e paradigmas anteriores à expansão das CVGs e das novas dinâmicas do comércio internacional. Dessa forma, a seguir buscaremos analisar mais detalhadamente o caso brasileiro, discutindo sua política comercial e, na medida do possível, os impactos do posicionamento do Pais nas negociações da OMC.

\section{Política comercial brasileira: um caso típico de aplicação de paradigmas anteriores à globalização}

Durante o governo Lula da Silva (2003-2010), em várias ocasiōes o ministro das Relações Exteriores e o próprio presidente da República declararam de maneira até enfática que a estratégia de comércio internacional a ser implementada pelo Brasil deveria ser "a de mudar a geografia comercial do mundo", referindo-se a categorias como "países ricos", "Norte-Sul", "economias emergentes" etc. Essa afirmação dava a entender que o governo buscava, sob esse mote, envidar esforços no sentido de diversificar as parcerias comerciais brasileiras, tornando o País menos dependente de parceiros tradicionais, isto é, de países considerados como economias desenvolvidas, em especial os Estados Unidos.

Essa preocupação evidencia, de um lado, a noção tradicional de que o Estado desempenha um papel central no estabelecimento dos fluxos de comércio e, de outro, a ausência da percepção de que as dinâmicas de comércio internacional, em sua parcela mais significativa, estão muito mais relacionadas à dispersão geográfica da produção do que à velha concepção de comércio na qual produtos acabados são produzidos em um país e chegam, por meio do comércio, aos consumidores residentes em outros países. Esse entendimento pode continuar valendo para o comércio de commodities, mas não vale mais para boa parte dos produtos industrializados, que respondem pela maior parte do comércio internacional. ${ }^{9}$

9 Em 1950, os bens agrícolas representavam 44,95\% das exportações mundiais. Em 2003, essa proporção havia se reduzido a 9,24\% (I. Santiago, Os regimes internacionais para a agricultura e a participação brasileira no comércio internacional, p. 59. Dissertação de Mestrado, UnB, 2005). 
Ao se considerarem as inúmeras manifestações oficiais referentes à Rodada Doha e a outras iniciativas voltadas à promoção das relaçôes comerciais, a conclusão é que, no Brasil, a análise das CVGs parece ainda não ter sido incorporada ao entendimento corrente tanto por parte dos analistas e quanto dos policy makers. Seja em declaraçôes oficiais, seja nas páginas econômicas da imprensa, é difícil observar qualquer menção a essa discussão, mesmo que de forma implícita, nas políticas adotadas ao longo do governo Lula da Silva. Com efeito, é notória a ausência dessa percepção acerca do papel desempenhado pelas CVGs no comércio internacional em documentos como a Estratégia Brasileira de Exportação (2008-2010), a Política de Desenvolvimento Produtivo e o Plano de Ação em Ciência, Tecnologia e Inovação (2007-2010).

Pode-se considerar que a política comercial dos oito anos do governo Lula da Silva esteve focada em cinco vertentes principais: i) promover o crescimento das exportaçôes; ii) diversificar as parcerias comerciais do País, buscando um maior relacionamento com países do hemisfério sul; iii) negociar acordos de preferências comerciais que respeitassem os "limites" brasileiros; iv) aplicação de instrumentos de defesa comercial e do sistema de solução de controvérsias da OMC; e v) incentivar o aprofundamento da integração regional. Uma breve análise dessas vertentes pode ser instrutiva para a melhor compreensão do caráter tradicional da política comercial praticada pelo governo brasileiro ao longo do governo Lula da Silva.

\section{Promoção das exportações}

Durante o governo Lula, as exportações brasileiras quase triplicaram, passando de US\$ 73,2 bilhões em 2003 a US\$ 201,9 bilhōes em 2010. É importante notar, no entanto, alguns pontos que evidenciam, em seu conjunto, o caráter tradicional da política comercial praticada. Em primeiro lugar, a participação das exportações sobre o produto interno bruto (PIB) caiu de $13,2 \%$ para $9,7 \%$ no período, o que pode ser explicado pela correspondente redução no índice de abertura da economia brasileira que recuou de $22,0 \%$ a $18,4 \%$, como pode ser visto na Tabela 1 . 


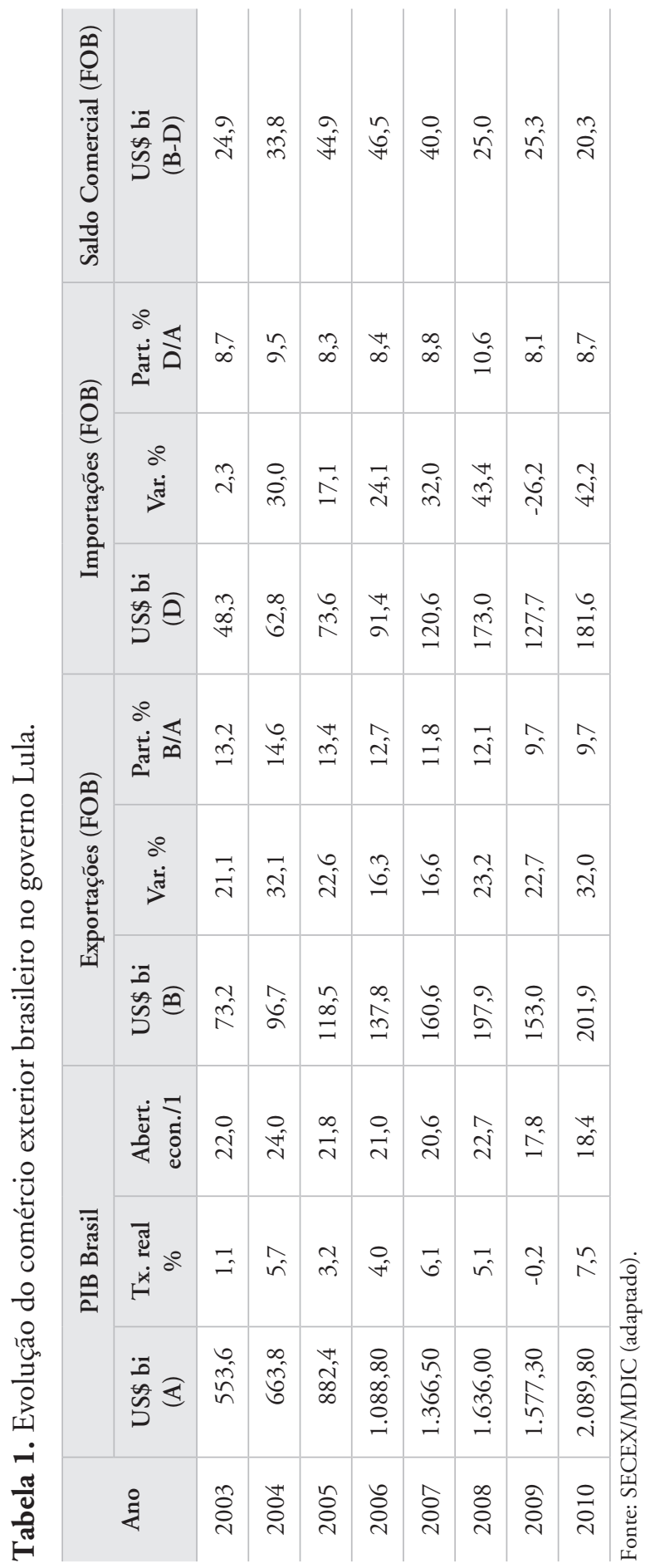


Com exceção do ano de 2009, que sofreu os reflexos da crise financeira internacional, as exportações brasileiras cresceram a uma média de $23,4 \%$ ao ano durante o período 2003-2010. Grande parte desse crescimento foi resultado do aquecimento da demanda internacional por commodities, com destaque para o mercado chinês. A participação de produtos básicos na pauta exportadora brasileira cresceu de $29,0 \%$ no início do governo Lula a 44,6\% em 2010, superando pela primeira vez desde 1980 as exportações de produtos manufaturados, que caíram para $39,4 \%$ em $2010 .^{10}$

No período de 2003 a 2010, o governo conseguiu atingir a meta estipulada pela política de desenvolvimento produtivo, ${ }^{11}$ que previa que as exportaçóes brasileiras representassem 1,25\% das exportações mundiais. Em 2010, o Brasil superou tal meta, passando a ser o $22^{\circ}$ maior exportador mundial, com $1,3 \%$ do comércio. ${ }^{12}$ A participação brasileira representa uma fatia pequena do comércio global, ficando atrás de todos os outros países que compóem o grupo BRICS. Em relação à abertura tarifária, a média simples da tarifa brasileira aplicada manteve-se estável ao longo do período, em torno de $13,6 \%{ }^{13}$

Em termos de gestão da política comercial, pode-se considerar que o governo Lula foi importante para iniciar a construção de um consenso na sociedade e no governo sobre a relevância do comércio exterior, assim como para o desenvolvimento de uma cultura exportadora entre as empresas, visto que a história recente do País esteve marcada por anos de fechamento comercial e substituição de importaçóes. Observou-se, no entanto, além do descompasso em relação às mudanças que estavam ocorrendo na estrutura do comércio internacional, a duplicação de açôes de promoção comercial entre os muitos órgãos governamentais com prerrogativas sobrepostas nessa área.

\section{Diversificação das parcerias comerciais}

Em conjunto com a promoção das exportações, o governo Lula deu ênfase à diversificação das parcerias comerciais brasileiras, procurando estabelecer um maior relacionamento com os governos dos países do hemisfério sul. Tal esforço esteve diretamente atrelado aos objetivos da política externa brasileira no período, que buscou uma maior aproximação com o continente africano, o Oriente Médio e a América do Sul. Essa vertente dizia respeito diretamente à ideia de "mudar a geografia comercial do mundo". É importante destacar que a

10 SECEX/MDIC - "Exportação brasileira por fator agregado - 1964-2010". Disponível em <http://www. desenvolvimento.gov.br/arquivos/dwnl_1303150699.xls>.

11 Politica de Desenvolvimento Produtivo. Disponível em <http://www.pdp.gov.br/paginas/macrometas. aspx\#ancora3>.

12 World Trade Atlas. GTI, Inc. Columbia, SC (USA).

13 WTO Tariff Profile. Disponível em <http://stat.wto.org/TariffProfile/WSDBTariffPFView. aspx? Language $=\mathrm{E} \&$ Country $=\mathrm{BR}>$. 
procura por novas parcerias comerciais não esteve ligada a uma ótica de melhorar a inserção de empresas nacionais nas cadeias produtivas globais, uma vez que a visão da estrutura do comércio internacional na perspectiva do governo Lula esteve predominantemente relacionada com a tradicional clivagem Norte-Sul, uma concepção claramente "estatocêntrica" das relações internacionais.

A mais notável mudança ocorrida no período 2003-2010 foi a ascensão da China como principal destino das exportaçōes brasileiras, superando os Estados Unidos. Em 2003, os Estados Unidos eram responsáveis por 22,8\% das compras internacionais de produtos brasileiros. Em 2010, a participação americana havia caído para 9,5\%. Essa queda de 13,3 pontos percentuais foi quase totalmente absorvida pela China, que em 2010 chegou a comprar 15,25\% das exportaçóes totais brasileiras, e no início do governo Lula as exportações para a China correspondiam a somente $6,2 \%$ do total de exportaçóes brasileiras - ou seja, um crescimento de 9,05 pontos percentuais.

Os esforços políticos de promoção comercial voltados para os países do hemisfério sul resultaram no aumento da corrente de comércio com a África, o Oriente Médio e os países asiáticos. No entanto, não se constata uma diversificação tão significativa dos destinos das exportaçôes brasileiras ao se compararem as participaçôes de blocos de países no total exportado nos anos de 2003 e 2010. Com base na Tabela 2, pode-se notar que os produtos brasileiros perderam mercado em parceiros tradicionais como Estados Unidos e União Europeia, sendo redirecionados em grande parte para a China e outros países asiáticos. Tal fato talvez seja melhor explicado pela demanda chinesa por matérias-primas do que pelas iniciativas diplomáticas brasileiras de diversificação comercial.

Tabela 2. Destino das exportações brasileiras (em \%).

\begin{tabular}{l|r|r}
\hline \multicolumn{1}{|c|}{ Blocos/países } & $\mathbf{2 0 0 3}$ & $\mathbf{2 0 1 0}$ \\
\hline África & 3,91 & 4,59 \\
Ásia & 11,71 & 21,85 \\
Aladi $^{(1)}$ & 17,68 & 20,41 \\
CCG $^{(2)}$ & 1,98 & 3,15 \\
China & 6,20 & 15,25 \\
Estados Unidos & 22,80 & 9,56 \\
Oriente Médio & 4,30 & 5,73 \\
SACU(3) & 1,02 & 0,66 \\
\hline
\end{tabular}

(1) Associação Latino-Americana de Integração; ${ }^{(2)}$ Conselho de Cooperação do Golfo; ${ }^{(3)}$ Southern African Customs Union [União Aduaneira da África Austral].

Fonte: adaptado de SECEX e World Trade Atlas.

Como parceiro tradicional, a fatia de produtos brasileiros importada pelo Mercosul tornou-se mais expressiva, sendo responsável por 11,19\% das exportaçōes brasileiras. É curioso notar uma queda nas exportações para a União Aduaneira da 
África Austral (SACU), bloco com o qual o Mercosul assinou acordo de comércio preferencial em 2008. Constata-se também um pequeno aumento na participação da África nas exportações brasileiras, mas um incremento modesto se comparado ao número de iniciativas, visitas políticas e missões comerciais empreendidas ao continente durante o governo Lula.

\section{Rodada Doha e negociação de acordos preferenciais}

O período 2003-2010 foi marcado pelo envolvimento brasileiro em um grande número de negociaçôes comerciais, mas com poucos resultados mensuráveis. A estratégia do governo brasileiro em privilegiar as negociações multilaterais no âmbito da OMC, especialmente na Rodada Doha, mostrou-se inócua em vista do impasse nas negociaçōes. É preciso reconhecer, no entanto, que a diplomacia do governo Lula foi bem-sucedida ao promover uma inflexão na dinâmica negociadora na OMC, abrindo caminho para a participação brasileira em processos de negociação e consulta antes reservada a pequeno grupo de países desenvolvidos, em particular os Estados Unidos, o Japão e a União Europeia. Entretanto, o governo brasileiro não usou essa oportunidade para propor alternativas inovadoras que pudessem trazer a negociação mais perto da realidade do comércio internacional atual, mantendo um espírito negociador baseado em conceitos e visões tradicionais do sistema internacional de comércio.

No início do primeiro mandato, destacaram-se as negociações da Área de Livre Comércio das Américas (Alca) e as negociações Mercosul-União Europeia. O projeto da Alca, após a constatação da existência de diferenças irreconciliáveis entre os negociadores acerca do escopo do acordo, saiu de pauta no final de 2005. Paralelamente, o processo Mercosul-União Europeia foi perdendo ímpeto nos anos seguintes, e a retomada oficial das negociações ocorreria somente em 2010, mas sem avanços significativos até o presente.

O Mercosul concluiu somente dois acordos de livre comércio durante o governo Lula, com parceiros cujo fluxo comercial é pouco significativo. ${ }^{14}$ O Acordo de Livre Comércio Mercosul/Israel foi assinado em 2007, já tendo entrado em vigor, ao passo que o acordo assinado com o Egito em 2010 encontrase em tramitação no Congresso Nacional. Em ambos os acordos o acesso livre de tarifas se aplica somente a bens, não incluindo serviços e investimentos.

Além dos acordos de livre comércio, o Mercosul concluiu um pequeno acordo preferencial de comércio com a Índia, abrangendo um conjunto de 900 linhas tarifárias. Em 2009, o Mercosul assinou um acordo similar com a SACU. Outras negociações foram iniciadas, como as conversaçōes com o Conselho de Cooperação do Golfo (CCG), o Paquistão, o Marrocos, a Jordânia, e um acordo

14 Ministério das Relaçōes Exteriores. “Balanço de Politica Externa 2001-2010”. Disponível em <http://www. itamaraty.gov.br/temas/balanco-de-politica-externa-2003-2010>. 
trilateral Mercosul-SACU-Índia. No âmbito da Associação Latino-Americana de Integração (Aladi), foram concluídos novos acordos de complementação econômica com o Peru, Cuba, e um acordo Mercosul-Colômbia/Equador/Venezuela.

Essa intensa movimentação do governo brasileiro reflete o caráter tradicional da visão predominante na formulação da política comercial: a ideia de que o comércio internacional está estruturado essencialmente sobre a venda de produtos acabados nos mercados internacionais. OMC, Mercosul, Aladi e SACU, além das inúmeras missões e negociações bilaterais, são todas instâncias intergovernamentais, onde são acordadas questôes como redução tarifária, regras de origem e defesa comercial, que privilegiam o comércio de produtos acabados, em especial commodities, mas pouco contribuem para a concepção mais moderna da existência de uma enorme massa de produtos globalmente produzidos.

\section{Defesa comercial e contenciosos na OMC}

O uso de medidas de defesa comercial pelo Brasil mostrou-se crescente durante o governo Lula, sendo este um instrumento escolhido para a proteção da indústria nacional frente ao aumento de importaçóes de determinados produtos observado no período. Segundo dados do Departamento de Defesa Comercial do Ministério do Desenvolvimento, Indústria e Comércio Exterior (MDIC), de 2003 a 2010 foram aplicadas 112 medidas definitivas, diante de 176 investigaçóes abertas. ${ }^{15}$ Nos oito anos anteriores ao governo Lula, o Brasil havia aplicado 66 medidas definitivas, entre dumping e salvaguardas.

O Brasil foi um dos países que mais utilizou o sistema de solução de controvérsias da OMC desde sua criação em 1995, tendo participado em 25 painéis como demandante, em 14 disputas como demandado e em 64 casos como terceira parte. ${ }^{16}$ Durante o governo Lula da Silva, o País conquistou algumas "vitórias" emblemáticas para o setor agroexportador, como foram os contenciosos dos subsídios americanos à cotonicultura, o de subsídios às exportações de açúcar concedidos pela União Europeia e a disputa sobre a taxa de equalização americana sobre importações de suco de laranja.

\section{Integração regional}

A política externa do governo Lula da Silva priorizou as relações com o Mercosul, buscando um aprofundamento da integração regional e a criação de um espaço de cooperação ampliado na América do Sul. Nas iniciativas de integração regional podemos identificar uma modesta preocupação do governo com o tema da

15 Ministério do Desenvolvimento, Indústria e Comércio Exterior. Relatório DECOM 2010. Disponível em <http://www.desenvolvimento.gov.br/arquivos/dwnl_1303755225.pdf>.

16 Disponível em <https://www.wto.org/english/tratop_e/dispu_e/dispu_by_country_e.htm>. 
integração produtiva como vetor para o crescimento do comércio e investimentos na região. Com efeito, por meio da Política de Desenvolvimento Produtivo (PDP), o governo brasileiro envidou esforços para articular as cadeias produtivas no âmbito do Mercosul e da America do Sul como um todo, com o objetivo de melhor utilizar o potencial de escala regional e aproveitar oportunidades em mercados globais. Em 2006, o Mercosul lançou o Programa de Integração Produtiva, e o governo brasileiro definiu quatro áreas iniciais de ação: (i) cadeia produtiva de petróleo e gás; (ii) adensamento da cadeia produtiva automotiva; (iii) cadeias produtivas ligadas ao turismo; e (iv) criação de grupos empresariais. ${ }^{17}$ Tais iniciativas foram complementadas por políticas de integração física da região e melhoramento de infraestrutura para o comércio.

É difícil avaliar os resultados concretos dessas iniciativas, levando-se em consideração o orçamento reduzido para os projetos, o baixo engajamento do setor privado nos países menores e as assimetrias das economias da região. Por outro lado, é preciso considerar também que uma maior integração produtiva exigiria melhorias efetivas para superar os gargalos em infraestrutura de portos, aeroportos e estradas da região. Nessas áreas são por demais evidentes as carências brasileiras às quais ainda se somam os entraves legais, fiscais e burocráticos que acentuam o fechamento da economia brasileira e praticamente inviabilizam iniciativas de integração internacional do sistema produtivo.

\section{Conclusão}

O fenômeno da globalização trouxe consigo mudanças estruturais importantes no comércio internacional. Entre essas mudanças está o fato de que, mais do que em qualquer outra área das relaçóes internacionais, o papel do Estado mudou sensivelmente e passou a sofrer forte concorrência de outros atores, notadamente as corporaçõos industriais, comerciais e financeiras. Como consequência, as apreciações e, em grande medida, o próprio conceito de multilateralismo no campo do comércio demandam uma revisão. As teorias utilizadas para interpretar os fenômenos internacionais falam de abordagens "estatocêntricas" e de abordagens onde o Estado perde sua importância, dividindo com outros atores as iniciativas no curso dos acontecimentos na esfera internacional. Nas relações econômicas, aparentemente a perda de importância relativa do Estado vem se tornando particularmente visível. A atuação de empresas - não apenas das grandes corporações transnacionais - ganhou relevância ao estabelecer negócios e oportunidades de investimento de natureza essencialmente internacional.

17 Agência Brasileira de Desenvolvimento Industrial (ABDI). Disponível em <http://www.abdi.com.br/Paginas/ acao_resumo.aspx?i=89>. 
Nesse quadro, são cada vez mais evidentes as desconexões entre os regimes vigentes, que continuam reconhecendo a centralidade do Estado, e a realidade composta de atores não estatais cuja relevância é crescente. Uma Rodada onde predominam os temas e as formas tradicionais de conduzir o comércio, baseadas em acordos e arranjos interestatais, como não poderia deixar de ocorrer, refletiuse numa agenda de pouca relevância para os principais interessados no comércio internacional: os conglomerados industriais, comerciais e financeiros - pequenos e grandes - responsáveis pela maior parte das transações econômicas internacionais.

Tarifas, subsídios e regras de origem afetam essencialmente o comércio de commodities, mas vêm perdendo relevância para os produtos manufaturados, cada vez mais dependentes de sistemas globalizados de produção, isto é, de um intenso e dinâmico fluxo de comércio de partes e componentes que irão resultar em telefones celulares, computadores, automóveis e outros produtos hoje fabricados e consumidos em toda parte. Os bens agrícolas, por exemplo, até meados do século 20 representavam quase metade das exportações mundiais; hoje representam menos de $10 \%$ do total, enquanto as condições de comércio de matérias-primas como petróleo, ferro e alumínio são negociadas à margem de Doha e da própria OMC.

Argumentamos no trabalho que as deficiências estruturais da agenda de Doha e a incapacidade de adaptação do modelo de rodadas comerciais aos novos desafios do comércio internacional têm contribuído para a estagnação das negociações. Os impasses na Rodada Doha são um reflexo dessa desconexão, e do descompasso que reside nos próprios países-membros da $\mathrm{OMC}$ que, em sua maioria, ainda não pautam suas políticas comerciais e suas estratégias de inserção internacional por essas novas dinâmicas do comércio internacional. Para compreender esse fenômeno, o caso brasileiro parece ser exemplar. A política comercial brasileira, no discurso e na prática, evidencia de forma bastante clara o porquê dessa desconexão entre a ação das autoridades, que investem em foros interestatais como Doha, enquanto a realidade do comércio mundial caminha celeremente em outra direção.

Com efeito, a política comercial brasileira durante o período 2003-2010 esteve desalinhada das novas tendências e realidades do comércio internacional, como foi discutido neste trabalho. Como resultado, é possível identificar um paradoxo na estratégia de inserção no comércio internacional do governo Lula da Silva: ao mesmo tempo em que o discurso político refutava uma aceitação qualificada como subserviente da tradicional divisão internacional do trabalho entre o Norte industrializado e o Sul pouco industrializado e clamava por uma realocação "soberana" da posição brasileira no comércio internacional, as políticas implementadas no período resultaram no retorno do País à condição de economia predominantemente agroexportadora. Como mostrado pelos dados apresentados, o declínio da importância relativa dos bens manufaturados na pauta de exportação foi visível ao longo do governo Lula da Silva e, em 2010, a participação de bens industrializados na pauta de exportaçóes brasileiras tornou-se menor do que $50 \%$, voltando a patamares que já se pensavam superados para sempre. 
Por fim, pode-se extrair também como conclusão que os desafios sistêmicos apresentados ao longo deste trabalho exigiriam uma resposta brasileira mais sofisticada do que a articulada pelo governo nos últimos anos. Como se pode observar com a experiência vivida por outros países, a adoção de uma concepção de "comércio integrado" - onde investimentos, inovação e exportação de valor agregado dialogam de maneira sistemática e profunda - talvez fosse capaz de fazer com que o Brasil retomasse a trajetória de uma economia cujo comércio exterior refletisse a sua face mais moderna, além de se constituir num fator mais dinâmico no processo de geração de empregos e de desenvolvimento tecnológico. A adoção de uma concepção mais moderna do comércio também refletiria positivamente no posicionamento brasileiro nas negociações da OMC.

\section{Referências bibliográficas}

Almeida, Paulo. R. "O Brasil como ator regional e como emergente global - Estratégias de política externa e impacto na nova ordem internacional”. Revista Cena Internacional. Brasília: UnB-IREL, vol. 9, nr. 1, 2007.

Bonaglia, F. and Goldstein, A. "More than T-shirts: The Integration of Developing Country Producers in Global Value Chains“, OECD Development Centre Policy Insights 49, OECD, Development Centre, 2007.

DICKEN, Peter. "Global Shift: Reshaping the Global Economic Map in the 21st Century". Fourth edition. London: Sage, 2003.

DICKEN, Peter. "Global Shift: Mapping the Contours of the World Economy”. London: Sage, 2007.

Dymond, B., and Hart, M. "Navigating new trade routes: the rise of value chains, and the challenges for Canadian Trade Policy”. C.D. Howe Institute Commentary. March 2008. <http://www.cdhowe.org/pdf/commentary_259.pdf>.

FLEXOR, Géorges. G. "Globalização Produtiva e Desenvolvimento industrial: a Análise das Cadeias de Valor Global”. In: Anais do XIV Encontro Nacional de Economia Política, 2009, São Paulo.

Gereffi, G. and Korzeniewicz, M. (eds). "Commodity Chains and Global Capitalism”. Westport: Praeger, 1994.

Gereffi, G. Humphrey, J, and Sturgeon, T. “The Governance of Global Value Chains”. Review of International Political Economy. 2005.

Glükler, J. "Economic geography and the evolution of networks". Journal of Economic Geography, Vol.7, no. 5. 2007.

Hopkins, T. and Wallerstein, I. "Patterns of development of the modern world-system". Review, vol. 1, no. 2, 1977.

Hopkins, T. and Wallerstein. "Commodity chains in the world economy prior to 1800 ". Review, vol. 10, n. 1, 1986. 
MDIC. "Estratégia Brasileira de Exportação (2008-2010)”. Ministério do Desenvolvimento, Indústria e Comércio Exterior. Brasília, 2008.

MOTTA VEIGA, Pedro. "As negociaçōes comerciais sob Lula: a estratégia nacionaldesenvolvimentista repaginada". Comércio e Política Comercial no Brasil. Desempenho, interesse e estratégias. São Paulo, SP, Editora Singular, 2007.

OECD. "Moving Up the (Global) Value Chain". Organisation for Economic Co-operation and Development, 2007. <http://www.oecd.org/dataoecd/45/56/38979795.pdf>.

Pereira, Lia. V. "A Integração Sul-Americana e a Agenda Brasileira de Acordos Preferenciais de Comércio: Avaliação e Perspectivas”. Pensamiento Iberoamericano p. 215-234, 2007.

Saraiva, Miriam. G. "O Segundo mandato de Lula e a política externa: poucas novidades". Carta Internacional, vol.2, no.1. Março de 2007.

Soares de Lima, M. R. "A política externa brasileira e os desafios da cooperação Sul-Sul”. Rev. Brasileira de Política Internacional, 2005.

Sturgeon, T. J. "Mapping Integrative Trade: Conceptualizing and Measuring Global Value Chains". International Journal Technological Learning, Innovation and Development. Vol. 1, no.3, 2008.

Vigevani, T. e Cepaluni, G. "A Política Externa de Lula da Silva: A Estratégia da Autonomia pela Diversificação”. Contexto Internacional, Vol. 29, no. 2, julho/dezembro, 2007.

VIOLA, Eduardo “Transformações na posição do Brasil no sistema internacional (1990-2005)”. Revista Plenárium, 2004.

Recebido em 24 de outubro de 2011 Aprovado em 29 de setembro de 2011

\section{Resumo}

Este trabalho tem como objetivo discutir os atuais desafios do multilateralismo tradicional no comércio, visíveis nos impasses da Rodada Doha, diante das novas realidades do comércio internacional globalizado, caracterizado pela dispersão e fragmentação da produção sob a lógica das cadeias de valor globais (CVG). O artigo discute a forma em que essas transformações estão desafiando pressupostos tradicionais do sistema multilateral de comércio e as negociações da Rodada Doha. Tomando o caso do Brasil como exemplo, o artigo argumenta que o descompasso entre a agenda negociadora e as novas realidades do comércio internacional reside nos próprios países-membros da OMC que, em sua maioria, ainda não pautam suas políticas comerciais e suas estratégias de inserção internacional por essas novas dinâmicas do comércio internacional. Por fim, o trabalho mostra que a política comercial brasileira durante a última década esteve desalinhada com essa nova realidade ao dar demasiada ênfase às formas tradicionais de negociação comercial, deixando de considerar as modificações essenciais ocorridas nos padrões de comércio na esteira do processo de globalização.

Palavras-chave: cadeias de valor globais (CVG); comércio internacional; economia política internacional; política comercial; Rodada Doha. 


\begin{abstract}
This paper discusses the current challenges of the multilateral trade system, which are reflected in the WTO Doha Round deadlock. The main patterns of trade have changed due to the rise of global value chains and the globalization of the world economy, characterized by an increasing dispersion and fragmentation of industrial production. The article discusses the way these changes are challenging traditional assumptions of the multilateral trade system and the WTO Doha Round negotiations. Taking Brazil as an example, the paper argues that the mismatch between the negotiating agenda and the new world trade realities dwells in the very WTO member countries, which, at a great extent, have not yet aligned its trade policies to the new dynamics of the international trade. Finally, we argue that during the last ten years Brazil's trade policy has not properly considered the important changes in the international trade patterns brought about by global value chains and economic globalization.
\end{abstract}

Keywords: global value chains; international trade; international political economy; Doha Round. 